\title{
THE ROLE OF MATERIALITY GUIDANCE IN RATIONALIZING PROFESSIONAL JUDGMENTS ASSOCIATED WITH MATERIALITY DECISIONS
}

\author{
Dr.Mohamed Wedad Alardi \\ Associate Professor of Accounting \\ College of Business - Rabigh \\ King Abdulaziz University
}

\author{
Dr.Sultan Mohamed Omar Altass \\ Assistant Professor of Accounting \& Finance \\ Vice Dean of Quality and Accreditation - Rabigh \\ College of Business - Rabigh \\ King Abdulaziz Uni
}

\begin{abstract}
This study aims to identify the problems of applying materiality concept, in addition to trying to propose a treatment for these problems by proposing and preparing a Professional guidance to guide the preparers when issuing their Professional judgments related to the concept of materiality. To verify the validity of the study hypotheses, researcher prepared a survey list consisting of sixteen questions, and the survey list was directed to four categories: Investment Fund Officials, Account Heads and Managers, Accredited Audit Offices, Academics Specializing in Financial Accounting. Researcher received responses to 69 lists out of a total of 95 lists with a response rate of $72.63 \%$. to verify the validity of the study hypotheses, statistical analysis was performed using descriptive statistics as well as statistical analysis using the Chi-Square Test. In addition, the Krusskal-Wallis test was performed to determine the extent of differences between the opinions of the study categories, and the tests showed that there were no differences between the opinions of the five study categories when answering the axes of the survey list, with the exception of limited exceptions that were interpreted in favor of the opinions of the audit offices in first and second hypotheses, and in favor of the opinions of heads and account managers regarding the fourth hypothesis.The study represents a contribution to accounting literature by identifying the problems of applying the concept of materiality, and trying to treat these problems by proposing and preparing a Professional guidance to guide the preparers when issuing their Professional judgments related to the concept of materiality. Finally, the research represents Contribution to the existing trend towards increasing the link between accounting research and the actual problems facing financial reporting preparers in the practice environment.
\end{abstract}

KEYWORDS: materiality, excessive disclosure, quantitative assessment, qualitative assessment, professional judgment, professional guidance, investor perspective 


\section{INTRODUCTION}

The objective of general-purpose's financial reports is to provide useful financial information to current or potential investors, lenders and other creditors in order to help them make decisions related to providing resources to the company (IASB, Oct 2015). The European Securities and Markets Authority (ESMA) confirmed that the information provided to users should be expressing the position, financial performance and cash flows, which requires not to delete important information or to included it with important information due to the consequent loss of financial statements of fair presentation, which negatively affects the process of making, and restoring a fair presentation requires the exact application of the concept of Materiality due to its paramount importance in all stages of preparing the financial statements represented in recognition, measurement, presentation and disclosure, taking into account that the accurate application of the concept of materiality requires careful study of the considerations governing the application of proportionality and how to rationalize the accompanying issuance of Professional judgments by the preparers (ESMA, 2011).

Concept of materiality is one of the main concepts used for the purposes of the financial report, and this concept represents the cornerstone of practicing the function of accountability of management, and materiality represents a guiding principle on which to determine the information appropriate to the needs of users (the minimum amount of information) as well as it represents a restriction on the quantity and details of the information required (The maximum), as it is considered one of the most popular concepts when preparing financial reports. The aforementioned is emphasized by the increased interest in it at the global level in order to overcome the problem of disclosure represented by insufficient appropriate information and to provide a lot of inappropriate information (Josef Baumüller, Michaela Linzatti, 2018). In the same regard, the International Accounting Standards Board (IASB) emphasized that a large part of the problem of excessive disclosure is due to the problems associated with the application of the concept of materiality and what these problems lead to in the dumping of important information with a lot of insignificant information, which requires the necessity of organizing the application of the concept of materiality (IASB, Oct, 2014). Institute of Chartered Accountants in England and Wales (ICAEW) confirmed that the concept of materiality is a basic concept in the financial report according to the list of principles issued by the Accounting Standards Board (ASB). (ICAEW, 2008):

Paragraph 3.28: Materiality represents the final test of what information should be provided in the financial report, while the qualitative characteristics of the quality of the information, if it is available, will mean that the usefulness of the information has been maximized. 
Paragraph 3.29: Materiality represents the Threshold of Quality for all information included in the financial statements. When insignificant information is provided, the resulting mess will impair the comprehension of the other information.

Paragraph 3.30: An element is significant if its omission or misrepresentation could reasonably have the effect on users' economic decisions or their assessment of management performance.

As result of Focusing on the concept of materiality, we conclude that it is not properly applied in practice, which is one of the main causes of the problem of excessive disclosure due to the consequences of imprecise application of relativity in providing a lot of insignificant information (IASB, Oct. 2015), and to confirm the above, some argue that the current disclosure is ineffective due to the following (Robert J. Bloom field, June. 2012):

1. Disclosure is efficient only if the preparers practice the selection method when determining what to disclose.

2. Available definitions of materiality fail to help the financial statement preparers to distinguish between significant disclosure, which results in providing useful information, and disclosure that duplicates previously known information, which leads to concealment of the material disclosure within the Haystack Disclosure, which obliges users to search for the significant disclosure to act as Needles in Haystack.

Accordingly, the research problem is determined by two variables, first variable is the deficiency in applying the concept of materiality, while second variable is the effects of this deficiency on the accounting disclosure, and researcher explains the components of the research problem as follows:

\section{1 - Problem of Deficiency by Applying the Concept of Materiality:}

The proper application of the concept of materiality is related to the need to understand the nature and characteristics of this due to the consequent provision of the ability to identify important information and separate it from what is not important. In addition to the need for the authors to realize that the chaos resulting from insignificant information often impedes the ability of users to understand the Financial Statements (FRC, 2012). The applying of the concept of materiality to professional practice is linked to the existence of many problems that have persisted for several decades and are still going on until now. The most important problems of applying the concept of materiality are identified by three problems: (William F. Messier Jr Nonna MartinovBennie, Aasmund Eilifsen, 2005):

1. Preparers' lack of knowledge of how investors used the financial statements when making an investment decision.

2. Authors and auditors, who are two different categories, issue importance decisions and thus there are differing views on the level of importance. 
3. There is little guidance on how to make Professional judgment by writers and reviewers when making the importance decision.

Emphasizing that there are problems related to the application of the concept of materiality. IASB and the FRC have concluded that the most important problems related to the application of the concept of materiality are the following $($ IASB, 2014) (FRC, 2011):

1. Lacking of an accurate understanding of the concept of materiality and the mechanisms of its application.

2. Using contradictory language within the standards.

3. Formulating criteria and what contained the obligation, such as "Shall disclose", or "As Minimum", which does not encourage the writers to issue a Professional judgment excluding certain disclosures as not important in order to avoid any violation of the formulation of the mandatory criteria.

4. The lack of clear objectives for the standards disclosure.

Accordingly, it becomes clear that there are many problems associated with applying the concept of materiality, which requires studying these problems and proposing the necessary tools to treat them or limit their negative effects.

\section{IMPLICATIONS OF DEFICIENCIES BY APPLYING THE CONCEPT OF MATERIALITY TO THE ACCOUNTING DISCLOSURE}

The role of the materiality concept in the problem of over-disclosure is evident based on the fact that the previously stated materiality application problems lead to the inability of the preparers to make accurate professional judgments. Former FASB President Leslie Seidman emphasized that the lack of guidance to control the issuance of materiality judgments is a major reason for Preparers to adopt a Defensive Disclosure Policy, which would entail meeting all disclosure requirements set out in the standards in order to avoid wasting time or facing pressure from reviewers, regulators or users (FASB, 2012). The application of proportionality in the exacerbation of the problem of excessive disclosure results through the writers' treatment of the financial statements as a compliance document and not a tool for communication with users. Therefore, the writers' resort to providing mechanically all the disclosure requirements in IFRS instead of applying professional judgment to determine what is significant to be provided and what It is insignificant to be excluded. The IASB indicated that this method is the main reason for the problem of excessive disclosure by the writers (IASB, Sep. 2017).

Ernst \& Young Global Limited (EY) also believes that addressing the problem of excessive disclosure requires careful application of materiality by issuing accurate Professional judgments by the writers. However, EY confirmed that the effectiveness of this proposal is limited by the presence of little guidance for writers to be able to make significant judgments on Accurate Materiality (EY, 2014). In the context of focusing on the concept of materiality as an entry point to treat the problem of excessive 
disclosure, the Institute of Financial Analysts (CFA) emphasized the need for continued discussion about what the materiality of accounting disclosure means, especially in light of the great chaos that Financial reports suffers from and the consequent blocking of the message to be conveyed to users. In addition, CFA emphasized that getting rid of the current chaos in financial reports requires the necessity to refine the concept of significant to support the ability of the writers to distinguish between what is significant and what is insignificant by preparing a Professional guidance that allows the writers to make their Professional judgment on the nature of the elements in the large gray area, which is the area where there are elements that require careful examination to determine what is significant and what is insignificant, which will support the ability of investors to issue informed decisions (CFA, 2013). In the same regard, KPMG affirmed that applying the concept of materiality to disclosure requirements represents a practical challenge for financial statement preparers, given that resolving this challenge will support the ability to communicate effectively with the users of financial statements as a result of focusing on providing significant information and reducing what it is provided from insignificant information. Verification of the above is linked to the existence of Professional guidance to guide the preparers when making their Professional judgments related to materiality (KPMG, 2018).

Based on the above, the research problem is determined in_the inaccurate application of the concept of materiality resulting from:

1. The lack of an appropriate Professional guidance to guide the preparers when issuing their Professional judgment about the significant of a specific disclosure.

2. The mandatory language of the standards and the associated tendency of the preparers to comply with the provision of all the disclosure requirements contained in the standards.

3. Using many synonyms for a significant word in standards, which leads to confusion of the preparers of financial statements.

The foregoing leads to flooding significant information with a lot of insignificant information, and thus the problem of excessive disclosure and the inability of users to build informed decisions arises.

\section{LITERATURE REVIEW AND HYPOTHESES DEVELOPMENT:}

There are many studies dealt with the different dimensions of the problem of materiality, and researcher presents some of the most important of these studies, divided according to whether they are studies issued by professional organizations or prepared by researchers.

\section{Features of Materiality}

The term materiality was first used in accounting at the beginning of the twentieth century and was intended to issue Professional judgments about the significance of information to determine the possibility of providing it to users. Since then the concept 
of materiality has witnessed many application issues that still pe'rsist until now, whether in relation to controlling the issuance of the preparers of the provisions of proportionality or agreement on the definition A unified relativism that builds on a fundamental pillar of the investor perspective (Josef Baumüller, Michaela Linzatti, 2018). Researchers believe that attempting to find proposals to solve the application issues requires determining the features that control this concept in first place, as an entry point to control the practical application of materiality, which will be discussed later in this section of the research. The main features of the concept of materiality are determined in accordance with what is mentioned in many studies as following:

\section{Materiality, a Common Concept:}

The IASB emphasized that the concept of materiality is a widespread concept throughout the financial reporting process with its four phases: recognition measurement - presentation - disclosure, and the standards state that the requirements contained therein are only implemented if their effect is material (IASB, Sep. 2017,). There are many criteria that contain indications related to materiality, in addition to what is mentioned in the intellectual framework, and these references can be identified, for example, by the following (ESMA, 2011):

Conceptual framework: Paragraphs QC 11, BC 3.18, BC 3.17

IAS1: Paragraphs 7, 29, 30, 31, 53, 86, 97, 121, 125

IAS8: Paragraphs 5, 6, 8, 41

IAS34: Paragraph 23

IASB also stressed that materiality is a pervasive concept that requires it to act as a filter to ensure that the information in the financial statements is concise, effective, and understandable. If the information in the financial statements has not been clearly summarized or compiled. This may result in an excessive amount of insignificant information, or significant information may be withheld, which makes users less able to understand the information contained in the financial report (IASB, Oct. 2015). With regard to the fact that the concept of materiality is a widespread concept throughout the stages of the financial report, it can be explained as follows:

\section{a. Materiality Concept in recognition and assessment stages:}

The IASB study confirmed that the standards include specific requirements for recognition, measurement, and uniformity. These requirements must be applied when the impact of their implementation is significant (IASB, Sep. 2017). The same matter was dealt with by IASB in another study, where it emphasized that the application of recognition and measurement requirements is only performed if they have a significant impact on the financial statements. IASB also presented a mechanism for applying materiality when recognizing, by clarifying that the company may follow an internal policy stipulating that expenditures are capitalized and considered as capital 
expenditures when they exceed a specified amount, and in the event that this amount is not exceeded, the amount is recognized as a normal expense. IASB confirmed that the administration, in this case, has made a Professional judgment regarding the fact that this departure from the application of IFRS does not have a significant impact on users' decisions, and IASB stressed that this policy must be re-assessed periodically to ensure that the unit's assumptions remain valid (IASB, Oct. 2015).

\section{b. Materiality Concept in presentation and disclosure stages:}

Failure to apply materiality is very common with regard to disclosure of information in notes, and this failure is represented in the reluctance of the preparers to make Professional judgments when determining the information that will be disclosed in the notes and those that will be excluded. This ultimately leads to over-disclosure and difficulty for users to understand the information disclosed in addition to difficulty finding significant information that is often obscured by insignificant information. IASB confirmed that the concept of materiality does not change when applied to notes, but the context of its application will be different because the notes have a different role from the financial statements in helping to achieve the objective of the financial report. IASB also clarified that the controls for the inclusion of information in the notes depend heavily on the proper application of the concept of materiality, in accordance with what was stated in IFRS. These controls are as follows (IASB, Oct. 2015):

1. Information that is not justified in presenting in the financial statements but is important to users must be disclosed in the notes.

2. Information that must be presented in the financial statements, therefore, not presenting them in the financial statements and only disclosing them with notes, will be insufficient.

3. Notes may include information that is not related to what is presented in the financial statements, but it is important information that affects users' decisions, such as unusual events after the date of preparing the budget, and information related to items not recognized in the financial statements.

4. What is stated in Paragraph 31 of IAS1 regarding the possibility of not providing for the disclosure requirements contained in the standards as long as this disclosure is not significant, in accordance with the Professional judgment of the preparer.

\section{Materiality is a General Principle:}

Materiality represents a general principle or an abstract concept that rely on the essence of the thing and how much does it affect users' decisions and in addition to the fact that its application is not limited to a specific context in the sense that it is applied to both the financial statements as well as to the notes $(I A S B, 2015)$ Furthermore, the concept of materiality is not only applied when preparing financial statements but also when performing the audit process and also when preparing non-financial reports. This is the 
reason why materiality is considered as a general principle that includes two aspects, one quantitative and the other qualitative (IASB, Nov. 2014).

\section{Materiality Decisions Reliance on Quantitative and Qualitative Assessment:}

IOSCO emphasized that assessing materiality requires taking into account the quantitative and qualitative dimensions of the item being assessed. IOSCO also called for the necessity of preparing a materiality directive, including examples to show how quantitative and qualitative aspects take into account materiality (IOSCO, Marc. 29. 2016). Related to the above is what was reached during the ESMA survey with the aim of determining the opinions of stakeholders about the considerations of assessing materiality. It was concluded through it that an accurate assessment of materiality depends on the inadmissibility of separating the quantitative and qualitative aspects when issuing the materiality judgment. The results of the survey confirm the current deficiency in practice, which is represented in the preparers 'adoption of the quantitative assessment method only. All studies have confirmed that it represents an insufficient indicator on its own to assess the materiality of a given item due to the possibility of an insignificant item according to the quantitative measurement. However, according to qualitative considerations, it represents an important item that must be provided for users (ESMA, Feb. 14. 2013), Researcher displays the quantitative and qualitative aspects as follows:

\section{Quantitative Aspect of Materiality Assessment:}

In a pioneering lecture by SEC (SAB No. 99), the quantitative limits developed by the miners over time to be relied upon when assessing materiality were discussed, and one of the most important quantitative rules adopted is the Rule of Thumb. It implies that the error or omission of an item is less than $5 \%$ of the profit is not a mistake or a significant omission (SEC, August. 12, 1999). The quantitative assessment of materiality is an inherent aspect of accounting literature as well as in practice, as the method based on using a 5\% limit of profits, as a measure of materiality is a common method. However, this method is absolutely reliant on it that may lead to a reduction in the quality of the financial report due to ignoring the qualitative factors It may be significant enough to consider an item that did not exceed the quantitative limit of relativity as a significant component. (Popa Irimie Emil, Sppan Georgeta Ancuţa, Fulop Melinda Timea, 2010) The quantitative measures most prevalent in the practice environment are identified as follows (Saher Aqel,2011):

a. Method of the Absolute Size of the Item.

b. Method of Fixed Ratio:

- $5 \%$ to $10 \%$ of the income figure.

- $5 \%$ of highest revenue or $10 \%$ of lowest revenue.

- $0.5 \%$ of total assets.

- $0.5 \%$ of total revenue.

- $1 \%$ of equity. 


\section{c. Canadian Method:}

The following limits are used to assess materiality:

- $2 \%$ to $5 \%$ of the total profit, in the event, that it ranges from zero to 20000 dollars.

- $1 \%$ to $2 \%$ of the total profit, if it ranges from 20,000 to $1,000,000$ dollars.

- $\quad 0.5 \%$ to $1 \%$ of the total profit, if it ranges from $1,000,000$ to $100,000,000$ dollars.

\section{d. Method of Blend}

Where 4 to 5 quantitative limits of materiality is calculated in accordance with the (b) method then the medium of all quantitative limits and the result will represent the limit that the item is significant at.

Researcher emphasizes what has been stated in many studies regarding the stability of the practice environment, that the quantitative limit used to assess proportionality should not be used in some cases in which a low materiality limit must be relied upon to ensure the provision of information on these cases such as (ESMA, Nov. 2011):
a. A case that does not align with legal and regulatory requirements.
b. Dealings with related parties, including board remuneration.
c. Irregular dealings (balances).
d. Any error that leads to redirecting performance from loss to profit or vice versa.
e. An error that affects the main indicators used to assess the unit's performance.

\section{Qualitative Aspect of Materiality Assessment:}

Materiality assessment of a specific item requires considering the nature and the surrounding conditions of the item, which is called the qualitative materiality assessment, and all Professional organizations have confirmed that qualitative materiality assessment is inseparable from quantitative assessment (Chiara Mio and Marco Fasan, Oct. 2013). The importance of a qualitative assessment of materiality is evident in light of the fact that the materiality decision cannot be made accurately without taking into account all the facts, the most important of which are the qualitative aspects related to the item under assessment. SEC confirmed the agreement with the Professional opinion of the FASB regarding the fact that the size of the element alone without regard to the nature of the clause and the circumstances of the issuance of the Professional judgment will not lead to a sufficient basis for the issuance of the judgment of materiality. With regard to the qualitative considerations that must be taken into account when assessing materiality, they are numerous that were mentioned in the SEC lecture (SAB No. 99) in which he identified nine quality factors that must be taken into account when assessing the level of significance of errors in the financial statements (SEC, August. 12. 1999): 
1. Whether the error is related to an item that must be measured accurately or through the estimation, which affects the level of accuracy of the assessment.

2. Whether the error is withholding a change in profits.

3. Whether the presentation hides the failure in meeting the analysts' expectations.

4. Whether the presentation turns the loss into profit and vice versa.

5. Whether the poor presentation relating to a portion of the business has been classified as material with respect to the unit's ability to generate profits.

6. Whether the poor presentation affects compliance with regulatory requirements.

7. Whether the poor presentation affects the unit's compliance with loan terms as well as other contractual terms.

8. Whether the poor presentation affects the raise in board remuneration.

9. Whether the poor presentation entails hiding an illegal dealing.

The previous nine qualitative factors represent an important reference when assessing the qualitative aspects of materiality, and one of the studies found that $17 \%$ (of a sample representing 76 American companies) did not depend on when assessing the materiality of an item on any of the previously stated qualitative factors. $30 \%$ of the companies usually bypass one or more of the nine qualitative factors when assessing the materiality despite the availability of this consideration. Finally, the study reached a variation in the companies 'dependence on qualitative considerations and that the fifth qualitative factor represents the most common qualitative factor when assessing the materiality of the sample companies, in addition to another qualitative factor, which is the third factor, but with a lesser percentage than the fifth factor (Andrewa. Actio, Jeffrey J. Burks, W. Bruce Johnson, 2019).

\section{The Relation of Materiality Decisions to Professional Judgment:}

The goal of financial reports is to provide users with a fair picture of their financial performance and position, so the preparers have to ask themselves what should be disclosed to provide a true and fair picture and are the information disclosed usefully, and these questions usually require the issuance of Professional judgments. There is no doubt that some of those who issue these judgments do not practice them properly, and many Professional organizations believe that the increase in the process of organizing the financial report has been associated with a decrease in the ability of the preparers to make Professional judgments and their increased focus towards fulfilling all the disclosure requirements contained in the standards even if they are not essential, which was a major cause of the problem of excessive disclosure. It was, therefore, indispensable to encourage the preparers to make their Professional judgment when applying materiality (ICAEW, Dec. 2013), and in a study by ICAEW, it was emphasized that the application of materiality must be based on the preparers' issuance of their Professional judgment, which must be based in turn. The preparers' awareness of the users' information needs and how they use this information when making decisions, which greatly helps the preparers to issue a Professional judgment to ensure that the users' information needs are met. ICAEW explained that preparers often need 
Professional guidance to guide them when making their Professional judgments related to decisions of importance (ICAEW, June. 2008).

Many studies have dealt with the assertion that the nature of the materiality decision necessitates considering it as a Professional judgment, and the justifications for considering the materiality decision as a Professional judgment are evident in the EFRAG's stated that the determination of materiality is not only related to the decision to disclose a specific element or not to disclose it, but it is also related to the rate decision making whether will (EFRAG, March 2016):

a. The item is presented separately in the financial statements or.

b. The item is grouped with another item and/or.

c. It is disclosed in the notes.

Researcher believes that controlling the preparers 'issuance of Professional judgment related to materiality requires building Professional guidance that governs the preparers' issuance of their Professional judgments, provided that this directive includes a precise definition of importance that allows the preparers the ability to identify the materiality elements, in addition to the need to accurately define the user who makes materiality decisions according to his information needs. Researcher also believes that providing the previous requirements will lead to the removal of unimportant information that obscures the important information, which means that the unit's performance and financial position will be more visible.

Based on the above, first hypothesis can be formulated as follows:

The multiplicity of materiality features as a general principle that is spread throughout all stages of preparing financial reports in its four stages.

\section{Materiality concept Application related to many challenges:}

KPMG study showed that there are eight main challenges facing the preparers when issuing their Vocational Judgment related to the decision of assessing Materiality, which necessitates them to be prepared to deal with these challenges and maintain a balanced approach that ensures meeting the needs of users, and these challenges are as follows (KPMG, 2014):

- Challenge One: Conducting a significance assessment process that is done independently of the components and working conditions of the unit.

- Challenge Two: Senior management should not participate in the stages of important decision-making.

- Challenge Three: Business can be very complex, which makes it difficult to obtain an accurate assessment of significance. 
- Challenge Four: Stakeholders' participation in significance assessment decisions represents a trend that many unit departments see as practical, costly and time consuming.

- Challenge Five: The difficulty of defining what the important topics are in light of the diversity of stakeholders' interests.

- Challenge Six: The important topics may be very broad and often overlapping.

- Challenge Seven: The possibility that there are many more important issues than the unit can manage.

- Challenge Eight: The repetition of the importance assessment every reporting period represents an unclear measure of its feasibility for many preparers.

\section{Based on that, second hypothesis can be formulated as follows:}

The many challenges associated with applying the concept of Materiality make it difficult for the preparers to issue Vocational Judgment related to this concept, which represents a major entry point to the problem of Excessive Disclosure.

Within the framework of the previous features of Materiality, which showed the extent of the spread of this concept in the financial reporting process as a general principle, its application requires the issuance of Vocational Judgments, which faces many of the difficulties that have led to multiple problems when applying this concept, which was a major reason for what the financial reports are currently suffering from Excessive Disclosure, and that's why it must find the appropriate solutions to deal with the problems of applying Materiality, which the researcher believes will be the main tool to reduce the negative effects of Excessive Disclosure. In the following, the researcher presents the approaches to the proposed treatment for the problems of applying Materiality, represented according to what has been reached by the research problem in proposing an amendment to define Materiality in addition to trying to prepare a Vocational Guidance to control Vocational Judgments related to Materiality.

\section{Professional Guidance that controls the Materiality decision:}

Researcher presents the following to a proposal to maintain a Professional Guidance that controls the issuance of Professional Judgment by the drafters in relation to decisions of relative importance, and researcher proposed that this proposal be presented according to the following order:

\section{The importance of maintaining Professional Guidance to control Materiality decision:}

One of the most important requirements for organizing the efficiency of disclosure is the distinction between important information and unimportant information, which represents a great challenge and requires the existence of a regulatory directive that directs the preparers when making decisions to distinguish between what is important and what is not important, that rationalization of dealing with the widespread use of the 
concept of Materiality requires the existence of a comprehensive framework and a coherent one that controls the application of Materiality, and the existence of this framework has become a goal that the business community wishes (Wally Auskas2003), and in a comprehensive study of $\boldsymbol{I A S B}$ that dealt with presenting and evaluating opinions for and against the issuance of a Professional Guidance controlling the decision of Materiality that was reached during consultative sessions were held with representatives of $(\boldsymbol{A S A F}),(\boldsymbol{G P F}),(\boldsymbol{I A A S B}),(\boldsymbol{I O S C O})$, in addition to reviewing academic literature to benefit from the findings of the accounting literature, and the study included the following opinions (IASB, Nov. 2014):

A. Opinions supporting the issuance of a directive controlling the Materiality decision:

Opinions in favor of issuing a Professional Guidance were based on the following:

a. There is broad support for issuing Professional Guidance from the preparers, auditors, regulators and users, as these parties believe that the principle of Materiality is not clearly understood and is not properly applied because many preparers focus on the quantitative aspect only when assessing importance.

b. The high level of subjectivity in the importance decision due to the absence of guidance directing the importance decision.

c. Desire to increase Professional awareness of the problems of applying Materiality and to show how to overcome them.

d. The need to provide more clarity regarding the disclosure requirements of the standards disclosure when they are important, which is believed to be a strong basis for reducing the reliance of the preparers on the use of the checklist method that leads to the users currently suffering from Excessive Disclosure.

\section{B. Opinions opposing the issuance of a directive controlling the Materiality} decision:

Opinions opposing issuance of a Professional Judgment were based on the following:

a. Having a directive will reduce the level of Professional Judgment of the preparers.

b. The possibility of conflict between the directive and local requirements related to decisions of importance.

c. The guidance alone will not be sufficient without reviewing the mandatory language used in the standards.

d. The necessity to focus on what is appropriate and not what is important. 
The IASB concluded with a decision of the importance of issuing a Professional Guidance that controls the Materiality decision due to the following considerations: -

1. Many of the problems encountered by the preparers when issuing their Professional Judgments regarding importance decisions in the absence of Professional Guidance to control these judgments.

2. Contradictory interpretations of the concept of Materiality at the global level in addition to implementation problems necessitate the existence of this guidance.

\section{Studies Supporting the Issuance of a Professional Guidance Governing Materiality Decision:}

In agreement with the IASB's conclusion of the necessity to issue a Professional guidance that governs the materiality decision, many studies have stated support for the IASB issuing a Professional guidance that governs the materiality decision, as follows:

1. EY believes that improving the effectiveness of disclosure requires additional guidance governing the application of materiality, and confirmed that the absence of this guidance currently makes the majority of preparers tend to focus on compliance (providing all the disclosure requirements contained in the standards) instead of focusing on effective communication with users by providing important information $(\boldsymbol{E Y}, 2014)$.

2. The FRC explained that the current chaos in financial reports is mainly caused by excessive disclosure resulting from the inundation of important information with a lot of unimportant information, which in turn produced as a result of the imprecise application of the concept of materiality, and therefore one of the most important approaches to reducing the current chaos in the financial report is the issuance of Professional guidance for the purpose of guiding the preparers when evaluating the importance of a particular element or disclosure, which will greatly reduce the risks involved in providing unimportant information $(\boldsymbol{F R C}, 2009$,).

3. The importance of having a coherent framework governing the issuance of the materiality decision is determined in that it will limit many of the biased disclosure decisions, and it will also help the preparers to understand the types of significance judgments accepted by the regulatory authorities. Likewise, the proposed guidance will help the compilers to realize the importance of taking into account the qualitative factors when issuing the relativity decision, which is what the practice environment currently lacks as there is no BrightLine governing the determination of what is important. (Andre A. Acito, Jeffrey J. Burks, W. Bruce. Johnson, 2019).

4. Following the IASB issuance of a practice statement entitled Application of Materiality to Financial Statements (previously described in previous studies) that included the formulation of a proposed Professional directive for controlling Professional judgments of materiality and many comments supporting the issuance of this guidance were issued by professional organizations such as IOSCO, AASB, ICAEW, EFRAG, ESMA (IOSCO, March 29. 2016,) (AASB, 
March 4. 2016) (ICAEW, Feb.12, 2016) (EFRAG, 2016) (ESMA, 2016), as well as from major auditing institutions and firms such as EY, PWC, KAMG, and Deloitte Touch (Deloitte Touch, Feb. 26. 2016) (EY, 2016) (PWC, 2016) (KPMG,2016).

a. Lack of accounting practice and literature for specific directives governing materiality measurement.

b. Emphasizing that the guidance should not act as strict rules, but it should act as an aid to the preparers when making a decision about the importance of disclosure and the feasibility of having this disclosure within the comprehensive financial reporting form, and the importance of the directive being brief.

c. The proposed guidance will have a major role in raising awareness among the preparers about the issue of excessive disclosure, which will motivate them to seek effective communication with users through the careful application of materiality.

d. The guidance would represent a common ground governing preparers' issuance of Professional judgments associated with identifying important or unimportant information.

Based on the above, researcher believes in the importance of issuing a Professional guidance to control and regulate the issuance of the preparers of the materiality's decisions. In the following, researcher presents the pillars that must be relied upon when formulating the proposed Professional guidance.

\section{Accordingly, third hypothesis can be formulated as follows:}

The issuance of a mandatory Professional guidance according to the established pillars is considered a major entry point for treating prepares issuance problems the Professional judgments related to materiality decisions.

\section{3- The Pillars of Building the Proposed Materiality:}

Within the framework of the professional and academic publications that have been presented, researcher believes that building a Professional guidance that controls and directs the Professional judgment related to relative importance requires the existence of major pillars to be relied upon when building this direction, and these pillars are defined as follows: -

\section{Relying on an investor's perspective:}

The conceptual framework of the financial report in paragraph 1.2 included a statement that the users of the financial statements are both current and potential investors and lenders as well as other creditors. Paragraph 1.8 also included a statement of the existence of a conflict in the information needs of user groups, which requires the necessity of identifying and providing financial information for the needs of the largest number of users, and According to CFA, the multiplicity of users' needs and the pursuit of their information needs have been associated with the continuous growth of lowquality information that often fails to warn investors of the occurrence of financial crises, even if warning signs are available, investors often fail to find them due to the 
fact that financial reports contain a lot of information that is not Important. And CFA confirmed that the above requires the necessity to rely on the investor's point of view when constructing the materiality decision so that what is important is determined based on the impact on the investor's decision, which will result in meeting the needs of all other users, that relying on the investor's perspective to determine what is important requires preparers' awareness of investor information needs and how they use it when making decisions. Without it, assessing significance will be a formidable challenge for preparers (CFA, 2013).

In the same regard, Faux believes that the basic reference that must be relied upon to determine the important information that must be included in the financial report must be the needs of the investor, given what this will lead to in reducing a lot of excessive disclosure, and Faux explained that relying on the investor's needs when determining what is important will be first step to achieve effective communication with different categories of stakeholders (FAUX J., 2012), and the same matter was addressed by CFA, meeting the needs of investors will greatly reduce the conflict of needs with the multiplicity of user groups, and meeting the needs of the investors will mean a higher ability to meet the needs of other categories of users (CFA, July. 2007), as KPMG explained that relying on the investor's perspective to determine what is Important it should be viewed as a comprehensive entry based on (KPMG, Oct. 2. 2017):

1. Determine the information needs of investors.

2. Introduce changes in recognition, measurement, and disclosure to improve the relevance of information to the needs of investors.

3. Focusing on effective communication with investors and other categories of users.

4. Supporting the level of transparency of the financial report.

Based on the foregoing, researcher believes that the information needs of investors should be the criterion upon which the relative importance decision is taken, so that what is important is considered based on his ability to make a difference to the investor's decision.

\section{Utilizing methods of estimating significance in non-financial reporting:}

The non-financial disclosure in corporate reports is critical in light of the desire to restore users' confidence in corporate behavior, as well as to help investors and other stakeholders make more informed decisions (Chiara Mio and Marco Fasan, Op. Cit, P. 5). Researcher follows on the methods of evaluating materiality when preparing nonfinancial reports, according to the institutions organizing the issuance of non-financial reports:

A- Materiality assessment procedures according to the integrated IR report. The framework for preparing the integrated report included seven principles and materiality was the fourth principle. The steps for assessing significance were defined as follows (IR, Nov. 2015): -

1. Building indicators to guide the evaluation process (what topics can be considered important and for whom). 
2. Filtering topics (by determining the importance of topics and determining priorities).

3. Setting limits for the report.

4. Determine the important disclosures.

5. Reconsidering the process and its procedures.

B- Procedures for assessing materiality according to the GRI

Materiality is one of the principles for determining the content of the sustainability report according to the GRI framework, and the GRI has identified several considerations that must be taken into account when assessing the importance of topics in the sustainability report (GRI, 2016):

1. The overall mission of the unit.

2. Information needs of stakeholders.

3. Commitments and commitments to standards or agreements that must be adhered to.

4. The impacts associated with the element being evaluated economically, environmentally and socially.

5. The effect of the component subject to evaluation on the decisions of stakeholders.

C- Materiality assessment procedures according to KPMG:

The KPMG proposed method for assessing significance in a non-financial reporting includes the following stages (KPMG, 2014):

1. Determine the purpose and scope of the report.

2. Identifying potentially important topics.

3. Classification of topics in the previous stage.

4. Collecting information on the impact and level of importance of topics in the previous stage.

5. Defining the priorities of the topics (determining importance).

6. Participation of senior management (evaluation of the steps that have been taken).

7. Testing the reasonableness of the evaluation results by presenting to the stakeholders (the necessity to document the results obtained from the stakeholders for reliance on them in the coming years).

\section{D- Materiality assessment procedures according to Accountability:}

The accountability framework for non-financial reporting includes three main steps that must be relied upon when assessing the importance of an element, and these steps are as follows (Accountability, August 2013):

1. Determine the important issues (according to the needs of the stakeholders).

2. Setting priorities.

3. Review (to ensure proper identification of priorities and their ability to meet stakeholders' needs).

Researcher believes that building a directive to control the issuance of Professional judgments related to materiality by the drafters should be done within the framework of taking advantage of the importance assessment stages according to non-financial 
reporting methodologies, given the prevalence and distinct ability of these reports to meet the information needs of their users.

\section{The necessity to include illustrative examples within the Professional guidance:}

Many local professional organizations and many major auditing institutions agreed on the necessity to include explanatory examples in the proposed Professional guidance to control the preparers' issuance of materiality, and they demanded that these examples include a detailed explanation of the factors that should govern the thinking of the authors of financial reports, and how to reach conclusions in addition to the necessity that they contain examples of guidelines illustrating the application of materiality in various ordinary and unusual situations (EFRAG, March 8, 2016, Op. Cit, Pp9-10), and the PWC confirmed its support for the inclusion of illustrative examples with Professional guidance of materiality provided that they contain sufficient details about the facts, that you may face and how to relate these facts to reach an accurate conclusion about the materiality (PWC, Feb 26. 2016).

In the same regard, ESMA believes that the presence of practical examples that include cases of how preparers make Professional judgments will make Professional guidance more useful for preparers and more relevant to the practice environment by clarifying how to deal with situations that are actually faced by preparers that call for Professional judgments (ESMA, Feb. 19. 2016), as AASB believes that the inclusion of examples with importance orientation will be useful for the preparers, provided that the examples are clear and varied and contain different situations that the preparers are exposed to in practice. And it often requires from them an additional effort such as (AASB, March 4. 2016):

- Transactions with related parties.

- Information related to pension plans.

- Information related to prose disclosure such as disclosure of risks arising from financial instruments in accordance with paragraph 33b of IFRS7.

Based on the above, researcher supports the inclusion of illustrative examples in the proposed Professional guidance of materiality, with the aim of showing the mechanisms for the preparers to issue their Professional judgment in different cases, provided that these examples include a presentation of how Professional judgments related to extraordinary transactions are issued, in addition to how to determine the importance of the disclosure requirements contained in the standards.

\section{Reducing term collision:}

According to the above, the standards contain many terms that may indicate that the element is important, such as Key, Principal, Significant. 5), and researcher agrees with this direction, and therefore the preparation of the proposed Professional guidance will be done within the framework of the work to reduce the conflict of terms in order to avoid confusion of the preparers, which is what researcher proposes to be by using only two terms which are important and not important. 


\section{Settling the argument whether Professional guidance is mandatory or not:}

Opinions varied about the level of obligation on the preparers towards the proposed Professional guidance due to the relative importance, as there are those who support that the Professional guidance is not binding and that it be issued as a statement of practice or in the form of educational versions for the preparers, and there are also those who support that this guidance be mandatory, and IASB has presented three directions on the extent to which the proposed career guidance is required (IASB, Nov. 2014):

\section{First direction: Issuing the Guidance in the form of an Executive Guidance (mandatory):}

Where the issuance begins in the form of Exposure Draft and requests comments from stakeholders on what modifications should be made to support the project's ability to address practice problems, followed by the final release in the form of mandatory executive guidance, and according to this method the application of what is provided by Professional guidance will be mandatory and will increase consistency across the world. However, there is potential for resistance from countries that have local guidelines governing the application of materiality, and IASB considers this method to be the most formal way to issue the proposed guidance.

\section{Second direction: Issuance of Professional Guidance in the form of Educational Materials (not mandatory):}

Where the guidance is issued in the form of educational publications that are not binding on the preparers, and according to this direction, the educational publications represent a more flexible tool in terms of the ability to comply with local requirements compared to the previous method, but there is a risk that these educational materials will be exceeded with the passage of time, which leads to a decline its impact on improving the application of the concept of materiality.

Third direction: Issuance of Professional Guidance in the Form of a Practice Statement (not mandatory):

The IASB followed this approach when issuing its Professional guidance in 2015 and IASB believes that this approach combines the advantages of the previous two approaches in terms of being a formal document with flexibility in terms of the ability to make modifications.

IASB staff has emphasized the accuracy of the third method for issuing the guidance in the form of a non-mandatory practice statement, and therefore the IASB does not obligate IFRS-applied units to apply this guidance, but it is the regulatory authorities in each country that should require units to apply this directive (IASB, Oct. 2015), and both AASB and EFRAG agreed with the IASB in terms of issuing the guidance in a non- mandatory way, but researcher objects to the fact that the guidance is not mandatory because this will greatly limit its effectiveness and will lose the ability to achieve. The consistency of the application of materiality across different countries of the world, and researcher believes that the positive effects associated with issuing this directive are related to the fact that this guidance is mandatory and the duty of 
application, and in this regard researcher agrees with IOSCO's assertion that the guidance being non-binding will greatly limit its global acceptance in addition to the consequences of this directive. Since it is not binding from not to apply it in the event of a local guidance, IOSCO also emphasized that the IASB publications on importance are intended to enhance and support consistency between countries and if this does not happen then the utility of these publications will diminish, and IOSCO called for the issuance of Professional guidance mandatory as part of IFRS, countries are therefore obligated to implement it, so that it is issued either as part of IAS1 or as part of the conceptual framework (IOSCO, March. 26, 2016), EY also called for the proposed relativity guidance to be included in the IFRS to avoid preparers from viewing the directive as unimportant and to issue it in the form of a non-mandatory practice statement (EY, Feb.26.2016.).

Based on the foregoing, researcher believes the reasonableness of what was reached by IOSCO and EY, where they requested that the Professional guidance be issued in a mandatory manner to ensure the realization of the expected benefits from it. Researcher also agrees with the ESMA's proposal that the guidance be issued as a mandatory implementation guidance attached to IAS1, in addition to the stipulation that the application of this guidance Professional is one of the requirements of a fair presentation contained in paragraph 15 of IAS1 (ESMA, Feb. 19. 2016).

\section{The Suggested Directive for Materiality:}

The continuing problems of applying the concept of materiality have been linked to the demand of many professional organizations and researchers to issue a Professional guidance directive that controls the issuance of Professional judgments related to materiality. It is taken into account that researcher relies on building the components of Professional guidance on the pillars previously stated, in addition to what has been stated from Professional guidance for the provisions of materiality in the following studies: -

1. IASB Materiality Orientation as a Practice Statement (1) entitled: Practice Statement (1): Application of Materiality to Financial statements (IASB, Oct. 2015)

2. The IASB Materiality Orientation as a Practice Statement (2) entitled: Practice Statement (2): Making materiality judgment (IASB, Sep. 2017)

3. ICAEW Materiality Guidance titled: Guidance on Materiality in Financial Reporting by UK Entities (ICAEW, 2008)

4. ESMA Materiality Guidance titled: Consideration of Materiality in financial reporting (ESMA, Feb. 14. 2013) (ESMA, Nov. 2011).

5. In addition to what has been reported in many studies on the controls of issuing Professional judgments related to the application of materiality.

Based on the above, researcher proposes that the proposed Professional guidance of the proposed materiality includes the following components (the lines listed in italics represent the proposed components of Professional guidance): 


\section{Who are the users and what are their information needs}

Researcher proposes to rely on the investor's perspective when determining the information needs, according to what was previously stated in first pillar of building the proposed Professional Guidance, and the problem in this regard is to determine the information needs of investors so that these needs act as a measure when determining what is important information and what is not important. And to determine the information needs of investors, researcher relies on what was issued by the FASB in Chapter VIII of the eighth concept of the concepts of the American intellectual framework entitled Notes to financial statements, which includes a statement of the information that investors need and how to assess its importance to determine the possibility of its disclosure in case it is important only. FASB has defined this information in three main components (FASB, August 2018), The main information needs for investors are also stated in the eighteenth, nineteenth, twentieth, and twentyone paragraphs of the Professional Guidance of ICAEW, as well as the twenty-one, twenty-two, and twenty-three paragraphs of the Professional Guidance of ESMA 2011, based on which the proposed wording is determined. For this part of the suggested Professional Guidance as follows:

The needs of investors are the main reference information that they depend on when determining the importance of an element, and the information that investors need to be able to make informed decisions is determined by the following:

\section{a. Information on the main elements, including disclosure of the following:-}

- Qualitative information on phenomena that investors consider important, especially with the inability to obtain information from other sources.

- Information on financial instruments, contracts, compliance with conditions, future flows associated with such contracts and their timing, risks related to flows of financial instruments or contracts.

- A description of uncertainties associated with estimates of key elements of the financial statements.

- Types of investments included in the portfolio of financial instruments.

- Types of inventory, whether raw materials, production under operation or finished products.

- Information about real estate property owned by the Unit.

- Revenue earned from the newly merged business.

- Information on fixed assets acquired as debt settlement.

- Information on the nature and properties of the components of the main elements.

- Information on unusual or non-recurrent key elements.

- Information about significant changes to elements of the main financial statements.

- Information on the inflows or outflows associated with the major elements.

- Information about assets controlled by the Unit that are not recognized in the financial statements due to their failure to meet the recognition requirements, such as the components of intellectual capital. 
- A description of the measurement methods used for the main or individual elements and an indication of the difference in the measurement method used.

- The accounting policies applied to the main elements, and whether there are any changes in the policies applied in the fiscal year report, with an explanation of the reason for the change if it occurs, and how the change affects the results of past years.

- Significant assumptions and provisions associated with the measurement methods used.

- Any additional information that management considers relevant and required in accordance with the investor's decision model.

Information on the unit of the report, which includes information on the unit of interest to investors and is determined as follows:

- General information about the unit and its main activities.

- Information on restrictions on the activities of the Unit or the benefits granted to it by the regulatory authorities.

- Information about related parties and transactions with them.

- Sectors of the unit.

- A description of the legal form of the units belonging to the unit.

- Any other information related to the unit that management considers important information for the investor decision form.

Information on past events, current conditions and considerations that could affect unit flows, including providing information on:-

- Current obligations on the Unit.

- The Unit's current obligations to other units.

- The level of uncertainty of flows associated with liabilities on the unit.

- Any violation of the laws, regulations or terms of contracts by the Unit.

- Any violation of unit rights associated with organization or contracts.

- Statement of the ability of the Unit to continue.

- The influence of circumstances or events on the unit's activities and workflow.

- The extent to which the circumstances or events the unit is exposed to are normal / or unusual.

- The unit's assessment of how events or circumstances affect future cash flows.

- Any obligations or rights arising as a result of past transactions, events or circumstances that are expected to meet the criteria for recognition of the future, indicating the expected flows associated with such obligations or rights.

- Any other information related to past events, current circumstances and considerations that management believes could influence the investor's decision model. 


\section{Definition of Materiality:}

\section{A- IASB defined Materiality at seventh paragraph of IAS1 as:}

Material omission or misrepresentation of items is of material importance if it can affect, individually or collectively, the economic decisions that users take on the basis of the financial statements. Materiality depends on the size and nature of the omission or the estimated poor supply in the surrounding circumstances and the size of the item, its nature, or a combination of both, may be the determining factor.

There is also another definition of Materiality included in $Q C 11$ of the IASB Intellectual Framework:

Information is of material importance if it can be reasonably expected that omission, misrepresentation, or withholding may affect the decisions made by the primary users of general purpose financial reports on the basis of those reports, which provide financial information about a particular reporting entity. Materiality is an aspect of suitability specific to each entity and is based on the nature of the items to which the information relates in the context of each entity's financial report, or on the size of these items, or on the nature and size together. Consequently, the board cannot set a unified quantitative limit on Materiality, or predetermine what would be of material importance in a given situation (IASB, March 2018, P.15).

B- FASB has modified the definition of Materiality adopted since 2010 in the American intellectual framework in paragraph $Q C 11$ to be as follows (it is the same definition that was canceled in 2010) (FASB Aug. 2018, Op. Cit, P.p. 1-12):

Relevancy and importance is defined by what influences or makes a difference to an investor or decision-maker, however the two concepts can be distinguished from each other, relevance is a general idea of the quality of useful information for investors, and importance is related to the unit, and the omission or misrepresentation of an element in the financial statements is important in light of ambient circumstances, the size of the element is likely to alter or influence the judgment of a rational person dependent on the report if the element is included or corrected.

$\boldsymbol{F A S B}$ also proposed adding the two paragraphs:

QC11/A: The paragraph includes an indication of the possibility of a decision not to disclose certain information because it is not important.

$Q C 11 / B$ : The paragraph includes clarifying the inability to issue a standard that takes into account all considerations affecting the Materiality process of making Vocational Judgment. 


\section{C- Definition of Materiality according to GRI}

The important aspects are those aspects that reflect the aspects of the economic, social and environmental unit that most influence the assessments of stakeholders (Jordi Morro Ribera, 2017).

\section{D- Definition of Materiality according to the Accountability Foundation}

It is the basis for determining the appropriateness and adequacy of a component of the unit and its stakeholders, and the important issue is defined as the one that will affect the decisions, procedures and performance of the institution and its stakeholders (IR, March. 2013).

\section{E- Definition of Materiality according to the $I R$}

The matter is important if it can significantly affect the evaluation of the providers of capital with regard to the unit's ability to generate value in the short, medium and long terms. When determining whether the matter is significant, or not, those charged with management and governance should consider whether the matter is it will materially influence the unit's strategy, business model, or capital (IR, March. 2013).

Within the framework of the definitions previously presented, the researcher proposes the following: -

1. The definition of materiality be limited to one paragraph to be included in

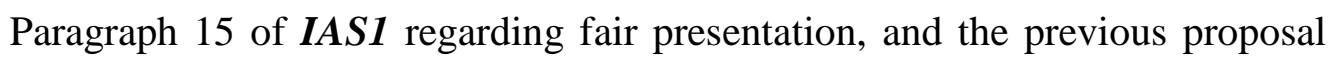
comes based on what the $\boldsymbol{K P M G}$ proposed regarding the necessity to consider amending the definition of significance a key part of the work agenda for effective communication and one of the most important requirements of fair presentation (KMPG, Jan. 15. 2018).

2. The second, third and fourth paragraphs of the proposed definition of the IASB as clarifying the mechanisms for the accurate application of the concept of material importance, the researcher believes that these paragraphs should be added to the proposed professional guidance for material importance.

3. The researcher believes that it is not feasible to repeat the definition of Materiality in $I A S 8$, which requires a proposal to delete the fifth and sixth paragraphs of $\boldsymbol{I A S \boldsymbol { ~ }}$.

4. The futility of including a definition of significance in the intellectual framework in order to reduce the confusion caused by the repetition of definitions of Materiality that the financial statement authors must rely on when determining what is significant.

5. Relying on the investor's perspective when drafting the proposed definition, and taking into account that the proposed Vocational Guidance in the following part of the research includes a statement of what information is important to investors, and this proposal comes in light of what was mentioned in many comments on the definition of $\boldsymbol{I A S B}$ which included that adding the keynote 
word to users will have a limited impact on practicing due to the multiplicity and conflict of needs of the main categories of users, which necessitates the identification of a specific category that leads to meeting their information needs to meet the greater extent of the needs of other groups of users.

Researcher believes that the essence of the definition of significance is the idea that information is important if its omission or misrepresentation will affect the users' decisions, and accordingly and in the context of evaluating both the current definition of significance as well as the definition proposed by the $\boldsymbol{I A S B}$ in addition to the other definitions previously presented, the researcher proposes the following definition of Materiality.

Information is important if it is reasonably expected that it will affect the decisions of a rational investor (individually or collectively) depending on the general purpose financial statements, and the proper application of the concept of Materiality requires an awareness that it is one of the most important requirements for achieving effective communication with investors, which requires reliance on Vocational Guidance for Materiality is included in the appendices to this standard.

\section{Features of materiality:}

Researcher suggests that the proposed Professional Guidance includes a submission of the features of materiality previously described in second section of the research in order to demonstrate the nature of the concept, which is closely related to the possibility of its proper application, and the formulation of this part of the Professional Guidance is determined as follows:-

The concept of materiality is characterized by a set of features and characteristics that are related to and affect the possibility of accurate application of this concept, and the features of the concept of materiality are as follows:-

a. A pervasive concept in the stages of the financial report; recognition, measurement, submission, and disclosure.

b. Materiality is a general principle.

c. Professional Judgment is the mainstay of the rigorous application of the concept of materiality.

d. An accurate assessment of materiality is related to both quantitative and qualitative evaluation.

e. Applying the concept of materiality is associated with many challenges.

\section{When disclosure is important:}

Practice Statement No. 2 issued by IASB included a statement that determining whether information is material is a matter of Professional Judgment that should be based on the needs of users of the financial report (Second part of this directive included examples of investor needs), as well as the facts and circumstances associated with the activity Unity, as confirmed by the Professional Guidance of the Institute of ICAEW in the 
sixth, seventh and eighth paragraphs that determining the important information depends on the size or nature of the item or both and it is a matter subject to Professional Judgment, the same was confirmed by the directive of ESMA 2011 in the nineteenth and twentieth paragraphs, and accordingly the wording of this part of the Professional Guidance is determined as follows:-

Determining the importance of the information depends on the size or nature of the item, or both, and it is a matter related to the issuance of the financial report compiler of its Professional Judgment, taking into account the following:

\section{a. Item size:}

The compilers of the financial statements shall arrive at the best estimate of the element subject to evaluation, stressing that the proportional judgment cannot be issued based on the absolute size of the item. For example, an amount represents an insignificant error in major international companies while in another company it represents a significant amount if it expresses Board remunerations, which represent an important element when holding investors accountable to management, as one of the objectives of the financial report.

\section{b. The nature of the item:}

The following considerations should be taken into account when assessing the importance of an element:

- Transactions or events related to the element being evaluated.

- Implications for transactions or events.

- The identity of the parties associated with the element being evaluated.

- Elements affected by disclosure of the element under evaluation.

c. Investors' needs represent basic reference information to determine whether the omission or misrepresentation of an element will adversely affect an investor's ability to make an informed decision.

d. Evaluating the materiality of the elements included in the notes has the same considerations for evaluating the materiality of the elements included in the financial statements. However, the qualitative factors are more important than the quantitative aspects when evaluating the materiality of the notes.

\section{When disclosure is not important:}

Researcher proposes to rely in the drafting of this part on the thirty-fourth and thirtysixth paragraphs of Practice Statement No. 1 issued by IASB, in addition to the eighth paragraph of the Directive of the Materiality of ICAEW, as well as the twenty-sixth paragraph of the Directive of the Materiality of ESMA 2011 It is taken into account that it was stated in Practice Statement No. 1 issued by IASB in the thirty-fifth paragraph that units are not prevented from disclosing unimportant information. However, the IFRS requires units to consider whether the unimportant disclosure will withhold important information. Researcher believes that the inclusion of this paragraph in the Statement of Practice No. $\mathbf{1}$ is due to what is stated in Paragraph $\mathbf{3 1}$ of IAS1, which did not explicitly prevent units from providing insignificant information, 
which was considered a major entry point for the compilers to adopt the Checklist approach to provide all the disclosure requirements contained in the standards regardless of the level of Its importance in order to avoid litigation or objection from the references or regulatory authorities, and researcher agrees with what was proposed by FASB of the necessity to explicitly state the necessity of eliminating unimportant disclosure and explicitly stipulating that omitting unimportant disclosure does not represent an accounting error (FASB, Sep. 24, 2014), accordingly, the proposed wording for this part of the proposed Professional Guidance is as follows:

Researcher believes that the previous paragraph limits its effectiveness greatly by the current wording of paragraph 31 in IAS1, which has been amended within the amendments to the IAS1 Disclosure Initiative (IASB, Dec. 2014) (IASB, March. 2014) (Added phrases for paragraph 31, written in italics, underlined)

\section{Paragraph 31 (amended paragraph):}

Some international financial reporting standards specify the information required being included on the financial statements and that include notes. An entity is not required to provide the specific disclosure required under the IFRS if the information resulting from the disclosure is not important. This is the case even if the IFRS contains a list of specific requirements or clarifies them. As a minimum requirement, an entity must consider whether additional disclosures should be provided when compliance with the specific requirements of the IFRS is insufficient to enable users of financial statements to understand the impact of certain transactions, other events and conditions on the financial position and financial performance of the entity.

\section{Adjustment assessment:}

A- IASB confirmed in the summary of the comments received about the amendments to Paragraph 31 that a number of comments indicated that these amendments represented a postponement to address the problem of materiality and the resulting excessive disclosure, and many comments included a request from IASB to move forward towards the implementation of the proposed project for issuing a Professional Guidance that controls Professional provisions related to materiality (IASB, Sep. 2014).

B- FRC and ESMA also confirmed the necessity of explicitly stipulating that it is impermissible to provide information that is not important because of the withholding of useful information resulting from its provision. Therefore, the wording of Paragraph 31 must be amended from (need not) the units to provide specific disclosure in IFRS if it is Unimportant) given that it is a formulation that allows the preparer to choose between providing or not providing unimportant information to (ust not). Units must provide specific disclosure in IFRS if it is not important), as the continuation of the current formula does not help to achieve the objectives of the financial report (ESMA, June. 23. 2014) (FRC, July 7, 2014), this is also called by EFRAG, where it confirmed the necessity of stipulate mandatory wording prohibiting the provision of unimportant information, which will allow the preparers to get rid of the concerns associated with the need to fully comply with the IFRS 
disclosure requirements to avoid objection by auditors (EFRAG, July. 22. 2014), based on the foregoing, researcher proposes to amend the wording of Paragraph 31 in IAS1 from the current wording (units not need to provide) to (units must not provide). Researcher believes that this formulation is consistent with the demand for the proposed guidance of relative importance by obliging the units not to provide insignificant information according to the fifth paragraph of this guidance.

\section{Obscure:}

In drafting this part of the proposed Professional Guidance, researcher relies on what was stated in the practice statements No. 1 and No. 2 issued by IASB, in addition to what was stated by EFRAG commenting on the proposed definition of materiality from IASB (EFRAG, Jan. 23. 2018). Accordingly, the wording of this part of the proposed Professional Guidance is determined as follows:

The intensive submission of non-significant information leads to the withholding of important information and hence the difficulty of finding important information by investors. The withholding of important information results in the failure of the Unit to achieve effective communication with investors. Some of the cases in which the withholding of important information is achieved can be explained by the following:

- Immersion of important information with unimportant information.

- Collection of information of a different nature or function.

- Not collecting (important) information of the same nature or function.

- Using unclear language, terminology, or concepts.

- Inclusion of information in places in the financial report where it is unlikely that this information will be searched for where it is included.

\section{Quantitative and qualitative assessment of materiality:}

Researcher relies on drafting this part on the foundations of the proposed Professional Guidance, in addition to what was stated in the statements of practice No. 1 and No. 2 issued by IASB, in addition to the sixth, eleventh, twelfth, twenty-sixth, twentyseventh, twenty-eight, twenty-ninth, thirty, and thirty-one paragraphs of Professional Guidance of the relative importance of ICAEW, as well as reliance on what was stated in the SEC lecture (SAB No. 99). Finally, reliance is made on what was stated in the tenth paragraph of the Professional Guidance of materiality ESMA 2013. Accordingly, the wording of this part of the proposed Professional Guidance is determined as follows:

The assessment of materiality depends on size, nature, Professional Judgment, and surrounding circumstances, and therefore the assessment of materiality depends on quantitative and qualitative factors (Paragraph 24 of Practice Statement No. 1 issued by IASB). The financial report preparers must adhere to the following guidelines when apply both types of evaluation:

a. Quantitative information is not the only factor to assess the importance of an element, as the evaluation of an element also depends on comprehensive qualitative information determined by the unit, and therefore it will not be appropriate when applying IFRS to rely on quantitative measures as the only 
measure of materiality (Paragraph 25 of Practice Statement No. 1 issued by IASB).

b. Setting quantitative limits is not a decisive issue in itself, but it may be useful when applying materiality. Quantitative limits provide a basis for the initial evaluation of an element whether this element is significant or not. For example, the element is not important if its value is less than a specified percentage of profit or net assets, however assessing the importance of this element also requires consideration of the nature of the component and the circumstances of the unit (Paragraph 26 of Practice Statement No. 1 issued by IASB).

c. There are cases in practice that are not usually considered when assessing quantitative aspects and include:-

- When deciding whether to disclose a particular policy, management must consider whether such disclosure is important to an understanding of the financial statements.

- When making a decision regarding the importance of information on uncertainties and assumptions about building probabilities, the nature of the element, its potential financial impact, and the timing of the associated cash outflows must be taken into account (Paragraph 27 of Practice Statement No. 1 issued by IASB).

d. There are some elements in which the evaluation of importance is more sensitive because it affects the decisions of investors, and also providing information about it is key to achieving effective communication with users, and these elements such as:-

- Elements whose lack of availability leads to non-compliance with legal requirements or loan conditions.

- Elements that represent the inputs to the future operations of the entity.

- Rare and Unusual Transactions (Paragraph 28 of Practice Statement No. 1 issued by IASB).

e. The qualitative factors that management must take into account when building its Professional Judgment about the importance of an element are determined below (SEC Lecture SAB No. 99), in addition to Practice Statements No. 1 and No. 2 issued by IASB:

- The potential impact of the element of evaluation on trends, especially the direction of earnings.

- Does the element of evaluation change the loss to profit or vice versa?

- The extent to which the element of evaluation affects normal or extraordinary profits.

- The potential impact of a misclassification between operating and nonoperating income

- The potential impact of the element being evaluated on the segment information.

- The potential impact of the element in question on the company's loan obligations, contractual provisions and regulatory provisions.

- The extent of the existence of regulatory or legal reports affecting the level of importance used in the evaluation.

- Does recognition of the element matter increase management rewards? 
- Is the element matter evaluated related to transactions involving fraud, conflicts of interest, breach of contractual provisions?

- How important disclosure is to known user needs such as:

- Earnings per share (EPS)

- The effect on purchase prices when interests are transferred.

- Impact on earnings expectations.

- Characteristics of the work or industrial sector to which the unit belongs.

- The extent of the possibility of negative effects as a result of the annual accumulation of the impact of a non-significant error.

- Organizational or operational characteristics of the unit that may affect the nature of an element.

\section{Professional Judgment:}

Researcher relies on drafting this part on the foundations of the proposed Professional Guidance, in addition to what was stated in the statements of Practice No. 1 and No. 2 issued by IASB, as well as the seventh paragraph of the directive of the relative importance of ICAEW, in addition to the twenty-two and twenty-three paragraphs of the ESMA 2011 material guidance, accordingly, the wording of this part of the proposed Professional Guidance is determined as follows:

When evaluating the level of importance of the information contained in the financial statements, management applies its Professional Judgment to make a decision about whether the information is reasonable to influence the decisions of investors based on financial reports. When issuing a Professional Judgment, the unit must consider:-

\section{a. The conditions of the facility.}

Professional Judgment is issued in light of the unit's circumstances, and these circumstances change over time. Therefore, the unit's circumstances affecting Professional Judgments of material importance must be reviewed every reporting period (Paragraph 12 of Practice Statement No. 2 issued by IASB).

\section{b. Investors' needs for information and how they use it:}

The management must issue its Professional Judgment to ensure the provision of the information that investors need (second paragraph of the proposed directive), and the decision models used by the investors must be clear to the management in order to be able to issue its Professional Judgment about the importance of an element in a manner that ensures the impact on the decision models.

c. The size of the element and the awareness of the purpose of its disclosure.

d. The nature of the element and this includes: -

- The transactions or events that led to the occurrence of the element.

- The implications of the transaction or event.

- The identity of the parties involved. 
e. The extent of the ability of the information subject to evaluation to achieve the goal of disclosure, there is no need to provide any other disclosure requirements as it will represent excessive disclosure that negatively affects investors' understanding of financial reports.

\section{Recognition and measurement:}

Researcher relies on the formulation of this part on the foundations of the proposed Professional Guidance, in addition to what has been stated in Practice Statements No. 1 and No. 2 issued by IASB, as well as directing the relative importance of ICAEW. Finally, the materiality guidance of ESMA 2013 is relied upon, accordingly the formulation of this part is determined of the suggested Professional Guidance is as follows:

Materiality requirements apply to recognition and measurement if there is a material impact on the financial statements (paragraphs sixty-one and sixty-two of IASB Statement of Practice No. 1), the unit may specify a specific amount to capitalize the expenditures spent on assets, and therefore the amount less than the importance limit is considered a normal expense to be included in the income statement, the alimony exceeding the significance limit is capitalized in accordance with the requirements of the seventh paragraph of IAS16 (Paragraph 9 of IASB Exercise Statement No. 2).

\section{Submission}

Researcher relies on the formulation of this part on the foundations of the proposed Professional Guidance, in addition to what is stated in the statements of Practice No. 1 and No. 2 issued by IASB, in addition to the fourth paragraph of the Professional Guidance for the relative importance of ICAEW. Finally, the paragraph is relied on the tenth of the ESMA 2011 Professional Guidance of material importance. Accordingly, the wording of this part of the proposed Professional Guidance is determined as follows:

The role of the financial statements is to provide an overview of the performance and the financial position, and this overview should be useful to investors in a way that ensures obtaining information about assets, liabilities, income, expenses, flows, distributions, claims on shares, on the management when issuing its Professional Judgment related to the elements that will be presenting them in the financial statements, taking into account the following considerations:

- Management's decision to determine elements to be presented in the basic financial statements separately because of their relative size or nature is an accurate decision that requires consideration of the degree of similarity or difference between the elements to determine whether these elements should be combined or presented separately (Paragraph 41 of Practice Statement No. 1 issued by IASB, in addition to the Twenty-three Paragraph of ICAEW).

- The management must take into account when determining the importance of an element ascribing this element to other elements, as well as its ratio to the subtotals included in the financial statement in which the element will be included, and the management must take into account the relationships between 
the financial statements, as well as identifying the elements that represent Signposts features useful for a solid link Financial statements with notes to help investors move through the financial statements (Forty-two paragraph of IASB Practice Statement No. 1).

- Management must take into account that the bad submission is significant if it is individually or collectively that it will reasonably affect the decisions of investors made on the basis of the financial statements (paragraphs sixtyseventh and sixty-eight of IASB Practice Statement No. 1, in addition to the fifth paragraph of Professional Guidance ICAEW).

- Management must take into account that it is possible that there is an element that should be brought to the attention of investors, despite the fact that it does not exceed the quantitative limit of relativity due to the nature of this element or the circumstances surrounding it that may lead to the element being able to make a difference to the decision of investors (Paragraph 24 of the ICAEW Professional Guidance).

- Management must take into account that it can amend the financial statements when ascertaining the existence of a significant misconduct before issuing those statements, regardless of the cost of this amendment. Moreover, management must consider the good effect resulting from correcting all aspects of the insignificant misrepresentation (Seventy-one paragraph of IASB Practice Statement No. 1).

- Based on the experiences related to the frequent issuance of professional judgments, the management may decide to give special importance to an element in the context of the performance trend and the profit margin achieved by other companies in the same sector, and the management should use a balanced approach in areas where achieving the degree of accuracy required by the report is difficult due to the high level of lack of making sure (Forty-one and forty-two paragraphs of ICAEW Professional Guidance).

\section{Notes:}

In formulating this part, researcher relies on what has been stated in the foundations of the proposed Professional Guidance, in addition to what is mentioned in the two practice statements No.1 and No.2 issued by the $\boldsymbol{I A S B}$, as well as the thirty-fifth

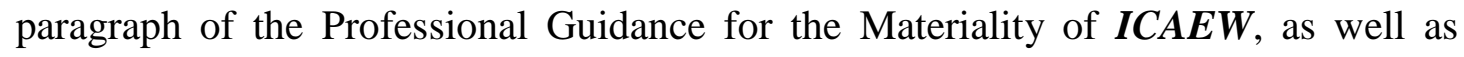
relying on the twenty-seventh, twenty-eighth and twenty-ninth paragraphs of Professional Guidance for Materiality ESMA 2011. Finally, relying on what was stated in the sixty-fourth, sixty-sixth, and Sixty-eighth, sixty-ninth, and seventy-first paragraphs of Professional Guidance for Materiality ESMA 2013. Accordingly, the formulating of this part of the proposed Professional Guidance is determined as follows:

Due to the structure of the financial statements and the limitations of what can be included in them, the notes include an explanation of the information presented in the financial statements in more detail in addition to supplementing the financial statements with additional information necessary to achieve the objective of the financial 
statements, although the concept of Materiality does not change when applied to the notes, but the context of the application will be different, given the different role of the notes compared to the financial statements in terms of contributing to the achievement of the objective of the financial statements (paragraphs 45-46-47-48 of IASB Practice Statement No.1). When issuing its professional judgment regarding the elements to be disclosed in the notes, the management shall take into account the following considerations

- When determining the importance of the information to be included in the notes, the practice and the majority of voational publications have stabilized the fact that the qualitative considerations (the seventh part of this proposed directive) have a special interest compared to the quantitative aspects, due to the nature of the majority of the information in the notes, which the quantitative side may not show its true level of importance (Paragraph 71 of ESMA 2013 Professional Guidance).

- The decision to include a specific disclosure depends on an assessment of whether the omission of this disclosure will affect the decisions of investors, which requires taking into account all the quantitative and qualitative considerations related to the assessment of Materiality (Paragraph 66 of the ESMA 2013 Professional Guidance).

- When assessing the importance of a specific disclosure related to one of the elements of the financial statements, management shall take into account the importance of the main component associated with it, as well as the decision to omit additional information about a significant key element represents a significant Professional mistake (paragraph 64 of the ESMA 2013 Professional Guidance).

- When determining the importance of a specific disclosure that is not related to the elements of the financial statements, management shall apply the same provisions of Materiality applied to the disclosures related to the elements presented in the financial statements (Paragraph 69 of the ESMA 2013 Professional Guidance).

- The management shall not treat the disclosure requirements contained in the IFRS as a Checklist that must be provided regardless of their importance. The unit shall not provide specific disclosures in the IFRS if these disclosures are not important due to the implications of including such information from Excessive Disclosure that often negatively affects the investor's ability to understand financial position and performance (paragraphs 49-50 of $\boldsymbol{I A S B}$ Practice Statement No.1, as well as Paragraph 10 of $\boldsymbol{I A S B}$ Practice Statement No.2, finally Paragraph 68 of the ESMA Professional Guidance 2013). 
- The unit shall conduct a comprehensive evaluation of the variety of information included in the financial statements or notes, and this evaluation can lead to a review of how the information is presented or disclosed in order to make the financial statements more understandable or give them an increased importance. Display or disclosure of additional information or the need to delete other information (Paragraph 33 of $\boldsymbol{I A S B}$ Practice Statement No.1).

- Providing additional information in the notes represents a Professional Judgment that must be based on the ability of this information to make a difference in investor decisions based on the financial statements and the accompanying notes. Examples of additional information that may be of interest to most investors are presented below (Paragraphs 28 and 29 of the ESMA 2011 Professional Guidance):

a. Professional Judgments issued by management when preparing financial statements.

b. Assumptions, models, and inputs used to measure the elements of the financial statements, in addition to information about interest rates and discount rates used. This information helps investors understand how the unit measured the items that were reported.

c. Disclosure of the sensitivity analysis in accordance with paragraphs $125-133$ of $I A S 1$, in order for investors to understand how the measurement of financial statement components fluctuates.

d. Disclosure of fair value amounts for the items included in the statement of financial position, in case of using other measurement methods other than fair value.

e. Information about the risks to which the unit is exposed and how the unit manages them in view of the effect of this information on investors 'evaluation of the expected cash flows and the time of their occurrence.

\section{Reviewing Disclosures in each Reporting Period:}

The management of the unit must continuously review each reporting period of the stages and work procedures followed when assessing materiality due to the change of importance criteria over time, and Accountability believes that consultants from inside or outside the unit can participate in this procedure in order to ensure an accurate and credible assessment of the quality of the stages. And the procedures for evaluating proportionality in previous periods (Accountability, Op. Cit, P.20), according to which the wording of this part of the proposed Professional guidance is determined as follows:

The unit must annually review the stages and procedures of evaluating materiality in light of the changing circumstances surrounding the unit or the increasing needs of investors for information, as well as reviewing the accuracy of the results of the materiality assessment in previous years. 


\section{Based on the above, the fourth hypothesis can be formulated as follows:}

The contents of the proposed Professional Guidance for Materiality are a significant pillar that can contribute to rationalizing the professional judgments associated with materiality decisions.

\section{Fourth: Experimental Study}

In the following, researcher deals with verifying the validity of the research hypotheses by preparing a survey list.

\section{Study Community:}

Researcher believes that the community whose views are being surveyed consists of the following categories:

1. Investment fund officials in joint stock companies whose shares are traded on the Saudi Stock Exchange (as a measure of investor opinions)

2. Chairmen and account managers of companies whose shares are traded on the Saudi Stock Exchange.

3. Certified Audit Offices.

4. Academics majoring in financial accounting.

Determining the sample and the response rate for each category:

1. Investment fund officials in joint-stock companies (as a measure of investor opinions), and their number reached eight, and questions were directed to them during personal interviews.

2. Chairmen and account managers in companies whose shares are traded on the Saudi Stock Exchange. Fifty-two lists were directed to them, and researcher received answers from forty-one heads or account managers with a response rate of $78.8 \%$.

3. Accredited Audit Offices, and twenty-four survey lists were directed to them, and researcher received answers from nine audit offices, with a response rate of $37.5 \%$.

4. Academics majoring in financial accounting, and their number reached eleven faculty members, and questions were asked to them during personal interviews.

\section{The Total Response Rate:}

The overall response rate is $72.63 \%$.

\section{Verify the Correctness of the Hypotheses:}

The validity of the hypotheses is verified by analyzing the answers of the study sample to the questions contained in the survey list.

\section{Descriptive Statistics and Chi-Square Test Results:}

Table (1) includes descriptive statistics (the Arithmetic Average and Standard Deviation) of the study sample responses to the related survey questions, in addition to 
Print ISSN: 2053-4086(Print),

Online ISSN: 2053-4094(Online)

the results of the Chi-Square Test (Descriptive statistics and the results of the ChiSquare Test Appendix 1). The rank of these paragraphs related to each Hypothesis as follows:

Table (1) Descriptive Statistics and Chi-Square Test results

\begin{tabular}{|c|c|c|c|c|}
\hline \multirow{2}{*}{$\begin{array}{c}\text { Questions } \\
\text { The Set of Questions } \\
\text { Associated with first } \\
\text { Hypothesis: }\end{array}$} & \multirow[b]{2}{*}{ Arithmetic Average } & \multirow[b]{2}{*}{ Standard Deviation } & \multicolumn{2}{|c|}{ Chi-Square Test } \\
\hline & & & The value & The Moral \\
\hline Q1 & 4.22 & 0.889 & 58.379 & 0.000 \\
\hline $\mathbf{Q 2}$ & 3.77 & 0.783 & 62.345 & 0.002 \\
\hline Q3 & 4.18 & 0.567 & 80.793 & 0.000 \\
\hline Q4 & 4.71 & 0.478 & 58.724 & 0.000 \\
\hline \multicolumn{5}{|l|}{$\begin{array}{l}\text { The Set of Questions } \\
\text { Associated with } \\
\text { second Hypothesis }\end{array}$} \\
\hline Q5 & 4.38 & 0.671 & 87.552 & 0.008 \\
\hline Q7 & 3.98 & 1.548 & 55.785 & 0.000 \\
\hline Q9 & 4.21 & 0.767 & 77.315 & 0.000 \\
\hline \multicolumn{5}{|l|}{$\begin{array}{l}\text { The Set of Questions } \\
\text { Associated with the } \\
\text { Third Hypothesis }\end{array}$} \\
\hline Q10 & 3.98 & 0.827 & 56.862 & 0.000 \\
\hline Q12 & 3.69 & 0.902 & 34.414 & 0.000 \\
\hline Q14 & 3.90 & 0.912 & 58.069 & 0.007 \\
\hline Q15 & 3.52 & 1.112 & 34.759 & 0.000 \\
\hline \multicolumn{5}{|l|}{$\begin{array}{l}\text { The Set of Questions } \\
\text { Associated with the } \\
\text { Fourth Hypothesis }\end{array}$} \\
\hline Q 16 & 3.76 & 1.097 & 62.345 & 0.000 \\
\hline Q18 & 3.69 & 1.314 & 8.552 & 0.000 \\
\hline Q20 & 4.29 & 1.243 & 17.345 & 0.004 \\
\hline
\end{tabular}

The previous table shows:

\section{With regard to descriptive statistics:}

The approval of most of the sample members on all the paragraphs related to the axes of the survey, and this is evidenced by the high mean values of all the paragraphs (greater than 3).

\section{As for the results of the Chi-Square Test:}

It is evident that there are differences between the frequencies distributed on the approval ratings for each of the survey paragraphs in favor of the consensus opinions on each paragraph, and the results of the Chi-Square test also indicate that these differences are considered significant and statistically significant, as the level of 
significance is less than $5 \%$. Hence, the majority believe the study hypotheses are correct, and accordingly, the study hypotheses are accepted.

\section{Comparison between the opinions of the study groups:}

To test the significance of the differences between the opinions of the five study groups (investment fund officials, accounts heads and managers, accredited audit offices, academics specializing in financial accounting, officials of disclosure departments at the Capital Market Authority and the Saudi Stock Exchange) about the problems of applying the Materiality concept and proposals for solution, the Krusskal-Wallis test was used, and this test is used to test the significance of the differences between more than two classes, and if the result of the Kruskal-Wallis test is significant (and that is when the Sig. 0.05) then that means that the differences between the four categories are significant, and those differences are in favor of the group with the largest average Mean Rank.

It was found that the result of the Kruskal-Wallis test is not significant (Appendix 2) as the level of significance is greater than 5\% for all paragraphs, indicating that there are no significant differences between the five groups in terms of their opinions regarding the problems of applying the Materiality concept and proposals for its solution. That is the third paragraphs (first hypothesis), the sixth (second hypothesis), and the eighteenth (the fourth hypothesis) as the value of the significance is less than 5\%, which indicates the existence of significant differences between the five categories, and those differences are explained by first and second hypotheses in favor of the opinions of audit offices, as they are interpreted with regard to the fourth hypothesis in favor of the opinions of accounts heads and managers. Accordingly, it can be concluded that there are no differences between the opinions of the five groups about:

1. Considering the Materiality concept as a widespread concept, its application is linked to many problems that exacerbate the problem of excessive disclosure.

2. Agree on the proposed definition of Materiality due to its role in limiting the application of Materiality problems.

3. Approval of the issuance and the contents of the mandatory Professional guidance to control the Professional judgments issued by the preparers related to the Materiality.

\section{CONCLUSION:}

The aim of the research was to define the problems of applying the Materiality concept, in addition to trying to propose a solution for these problems by proposing an amendment to define Materiality, as well as proposing and preparing a Professional guidance to guide the preparers when issuing their Professional judgments related to the Materiality concept. The research was divided into five sections as follows:

First Section dealt with the research methodology, and Second Section dealt with identifying the main features of Materiality as an entry point to find approaches to 
solving the problems of its application, and The Third Section dealt with first proposal to address the problems of applying Materiality, which is to amend the definition of Materiality contained in the seventh paragraph of IAS1, and The Fourth Section included: presentation the foundations of the proposed Professional guidance to adjust the judgments of Materiality was followed by a presentation of the components of this proposed guidance, and finally The Fifth Section included the test study to verify the validity of the research hypotheses using descriptive statistics, as well as the Chi-Square test was used and finally the Kruskal-Wallis test was used, researcher reached the following results: -

1. The assessment of Materiality in the practice environment is linked to many problems.

2. The problems of applying Materiality and the preparers' fear of accountability lead to the provision of all the disclosure requirements contained in the standards, regardless of their importance, which in turn exacerbates the problem of excessive disclosure.

3. The proposed definition of the Materiality leads to the contribution to solving the problems of applying Materiality, where emphasis was placed on defining what is important information, and users were identified by the rational investor to ensure the limitation of excessive disclosure with the multiplicity of user groups, and finally the term Could was replaced by the term Would which expected to lead to an increase in the Materiality level.

4. The proposed mandatory Professional guidance plays an important role in controlling the Materiality provisions issued by the preparers, which is currently lacking in the practice environment.

\section{References:}

- Accountability, Redefining Materiality II: Why it Matters, Who's Involved, and What It Means for Corporate Leaders and Boards, August 2013.

- Andrew A. Acito , Jeffrey J. Burks, W. Bruce Johnson, The Materiality of Accounting Errors: Evidence from SEC Comment Letters, Contemporary Accounting Research ,Volume36, Issue2, Summer 2019.

- Brennan, Niamh; Gray, S. J., The impact of materiality: accounting's best kept secret, Journal of Accounting Research, IV (1) , 2007.

- Chiara Mio and Marco Fasan, Materiality from financial towards non-financial Reporting, Working Paper Department of Management at Università Ca' Foscari Venezia n. 19/2013, October 2013.

- Chiara Mio , Marco Fasan, The Determinants of Materiality Disclosure in Integrated Corporate Disclosure, Department of Management, Università Ca' Foscari Venezia Working Paper No. 2014/9,Jun 2014.

- Deloitte Touch, Exposure Draft ED/2017/6 Definition of Material, 1 December 2017.

- Deloitte Touch, Exposure Draft - IFRS Practice Statement - Application of Materiality to Financial Statements February 19.2016. 
European Journal of Accounting, Auditing and Finance Research

Vol.10, No. 1, pp.71-112, 2022

Print ISSN: 2053-4086(Print),

Online ISSN: 2053-4094(Online)

- Ernst \& Young Global Limited (EY), Improving disclosure Effectiveness, July 2014.

- Ernst \& Young Global Limited (EY),Invitation to comment - Exposure Draft ED/2015/8 - IFRS Practice Statement: Application of Materiality to Financial Statements, February 26. 2016.

- European Financial Reporting Advisory Group (EFRAG), ED/2017/6 Definition of Material - Proposed amendments to IAS 1 and IAS 8 , 23 January 2018.

- European Financial Reporting Advisory Group EFRAG, Re: Disclosure Initiative (Proposed amendments to IAS 1), July. 22. 2014.

- European Financial Reporting Advisory Group (EFRAG), Re: ED/2017/6 Definition of Material - Proposed amendments to IAS 1 and IAS 8, January 23, 2018.

- European Financial Reporting Advisory Group (EFRAG), Re: Exposure Draft ED/2015/8 IFRS Practice Statement: Application of Materiality to Financial Statements, 8 March 2016.

- European Securities and Market Authority (ESMA), Consultation Paper Considerations of materiality in financial reporting, Nov, 2011.

- European Securities and Market Authority (ESMA), Feedback Statement: Considerations of materiality in financial reporting, Feb.14, 2013.

- European Securities and Market Authority (ESMA), Ref: Exposure Draft IFRS Practice Statement: Application of materiality to Financial Statements, , February 19.2016.

- European Securities and Markets Authority (ESMA), The IASB's Exposure Draft Proposed Amendments to IAS 1 - Presentation of Financial Statements under the Disclosure Initiative, June. 23. 2014.

- Faux, J. Environmental event materiality and decision-making. Managerial Auditing (3), Journal 27, 2012.

- Financial Accounting Standards Board (FASB), Conceptual Framework for Financial Reporting: Chapter 3: Qualitative Characteristics of Useful Financial Information, August 2018.

- Financial Accounting Standards Board (FASB), Conceptual Framework for Financial Reporting: Chapter 3: Qualitative Characteristics of Useful Financial Information, September 24, 2015.

- Financial Accounting Standards Board (FASB), Conceptual Framework for Financial Reporting: Statement of Financial Accounting Concepts No. 8: Chapter 8, Notes to Financial Statements, August 2018.

- Financial Accounting Standards Board (FASB), FASB Chair Examines CostBenefit Analysis and Disclosure Overload, July. 10, 2012.

- Financial Accounting Standards Board (FASB), Notes to Financial Statements(Topic 235): Assessing Whether Disclosures Are Material, September 24, 2015.

- Financial Reporting Council (FRC), Cutting Clutter, Combating clutter in annual reports, 2011.

- Financial Reporting Council (FRC), louder than Words: Principles and actions for making corporate reports less complex and more relevant, 2009. 
European Journal of Accounting, Auditing and Finance Research

Vol.10, No. 1, pp.71-112, 2022

Print ISSN: 2053-4086(Print),

Online ISSN: 2053-4094(Online)

- Financial Reporting Council (FRC), Request for information on the application of materiality, 3 June 2014.

- Financial Reporting Council FRC, Response to Exposure Draft 'Disclosure Initiative (Proposed amendments to IAS 1), July 7. 2014.

- Financial Reporting Council (FRC), Thinking about disclosures in a broader context, October 2012.

- Global Reporting Initiative (GRI), GRI 101: FOUNDATION,2016.

- Gunther, Samuel P, What Is Materiality? SEC \& PCAOB v. FASB \& ASB, Accounting Policy \& Practice Report 8.11, May 25, 2012.

- Institute of Chartered Accountants in England and Wales (ICAEW), ED/2017/6 Definition of Material - Proposed amendments to IAS 1 and IAS 8, January 15, 2018.

- Institute of Chartered Accountants in England and Wales (ICAEW), Financial Reporting Disclosure s: Market and Regulatory Failures information for better markets initiative, December 2013.

- Institute of Chartered Accountants in England and Wales (ICAEW), FRED 53 Draft Amendments to FRS 101 Reduced Disclosure Framework, March. 21. 2014.

- Institute of Chartered Accountants in England and Wales (ICAEW), GUIDANCE ON MATERIALITY IN FINANCIAL REPORTING BY UK ENTITIES,2008.

- Institute of Chartered Accountants in England and Wales (ICAEW), Rep 42/16 Application of Materiality to Financial Statements, February,12, 2016.

- International Accounting Standards Board (IASB), CMAC meeting, Disclosure Initiative: Materiality, 27 February 2014.

- International Accounting Standards Board (IASB), Conceptual Framework for Financial Reporting, March 2018.

- International Accounting Standards Board (IASB), Definition of Material Proposed amendments to IAS 1 and IAS 8, September 2017.

- International Accounting Standards Board, IASB, Disclosure Initiative amendments to IAS 1, Dec.2014.

- International Accounting Standards Board (IASB), Disclosure Initiative: Materiality, 2015.

- International Accounting Standards Board, IASB, Disclosure Initiative: Proposed amendments to IAS 1: feedback summary Sep.2014.

- International Accounting Standards Board, IASB, Disclosure Initiative: Proposed amendments to IAS 1, March, 2014.

- International Accounting Standards Board (IASB), IFRS Practice Statement, Application of Materiality to Financial Statements, Oct, 2015.

- International Accounting Standards Board (IASB), Materiality, Oct, 2014

- International Accounting Standards Board (IASB), Practice Statement 2, Making Materiality Judgements, September 2017.

- International Accounting Standards Board (IASB), STAFF PAPER: Disclosure Initiative: Materiality, November 2014. 
- International Accounting Standards Board(IASB), STAFF PAPER: Disclosure Initiative: Materiality- Responses from national standard-setters, 22-24 September 2014.

- International Integrated Reporting Council, (IIRC), Materiality Background paper for <IR>, March 2013.

- International Integrated Reporting Council, (IIRC), Materiality in <IR> Guidance for the preparation of integrated reports, November 2015 .

- Jordi Morrós Ribera, Materiality in sustainability reporting: multiple standards and looking for common principles and measurement. The case of the seven biggest groups in Spain , EUROPEAN ACCOUNTING AND MANAGEMENT REVIEW, VOLUME 4, ISSUE 1, ARTICLE 6, 108-147, NOVEMBER 2017.

- Josef Baumüller, Michaela-Maria Schaffhauser-Linzatti, In search of materiality for nonfinancial information-reporting requirements of the Directive 2014/95/EU, The journal Sustainability Management Forum (SMF), 26, Aug. 132018.

- KPMG, Comment letter, Discussion paper DP/2017/1: Disclosure Initiative: Disclosure Principles, October,2, 2017.

- KPMG, Comment Letter on Exposure Drafts: "Conceptual Framework for Financial Reporting - Chapter 3: Qualitative Characteristics of Useful Financial Information" (File Reference No. 2015-300), December 8, 2015,

- KPMG, Comment Letter on Exposure Draft ED/2017/6 Definition of Material (Proposed amendments to IAS 1 and IAS 8), 15 January 2018.

- KPMG, Comment Letter on Exposure Draft ED/2015/8 IFRS Practice Statement: Application of Materiality to Financial State, February 19 .2016.

- $\quad K P M G$, Sustainable Insight The essentials of materiality assessment, 2014.

- Popa Irimie Emil, Şpan Georgeta Ancuţa, Fulop Melinda Timea, QUALITATIVE FACTORS OF MATERIALITY - A REVIEW OF EMPIRICAL RESEARCH, Annales Universitatis Apulensis Series Oeconomica, 12(1), 2010.

- $\quad P W C$, Expostire Draft: IFRS Practice Statement: Application of materiality to financial statements (ED/2o15/8), 26 February 2016.

- Robert J. Bloomfield, A Pragmatic Approach to More Efficient Corporate Disclosure, Accounting Horizon, Vol. 26, No. 2, June 2012.

- Saher Aqel, Auditors' Assessments of Materiality Between Professional Judgment and Subjectivity, Accounting and Auditing AUDOE, Vol 7, No. 4/2011.

- Shane Heitzman,Charles Wasley,Jerold Zimmerman, The joint effects of materiality thresholds and voluntary disclosure incentives on firms' disclosure decisions, Journal of Accounting and Economics, Volume 49, Issues 12, February 2010.

- SECURITIES AND EXCHANGE COMMISSION (SEC), File Reference No. 2015-300, Proposed Amendments by the FASB to Concepts Statement No. 8, Conceptual Framework for Financial Reporting, July 11, 2017.

- SECURITIES AND EXCHANGE COMMISSION (SEC), SEC Staff Accounting Bulletin: No. 99 - Materiality, August 12, 1999. 
- Susie Ruqun Wu, Changliang Shao, Jiquan Chen, Sustainability Review, 3233, Oct 2018.

- The Australian Accounting Standards Board (AASB), IASB ED/2015/8 IFRS Practice Statement: Application of Materiality to Financial Statements, March 4, 2016.

- The Chartered Financial Analyst Institute, CFA, A Comprehensive BusinessReporting Model Financial Reporting for Investors, July 2007.

- The Chartered Financial Analyst Institute, CFA, Financial Reporting Disclosures Investor Perspectives on Transparency, Trust, and Volume, July.2013.

- The International Organization of Securities Commissions (IOSCO), RE: Practice Statement: Application of Materiality to Financial Statements, 29 March 2016.

- Wally Auskas, Shades of materiality, Canadian Accounting Perspectives 2.2, 2003.

- William F. Messier Jr, Nonna Martinov-Bennie, Aasmund Eilifsen, A Review and Integration of Empirical Research on Materiality: Two Decades Later, Auditing A Journal of Practice \& Theory, August 2005. 